\title{
Epidemiological appraisal of studies of residential exposure to power frequency magnetic fields and adult cancers
}

\author{
Chung-Yi Li, Gilles Thériault, Ruey S Lin
}

\begin{abstract}
Objectives-To appraise epidemiological evidence of the purported association between residential exposure to power frequency magnetic fields and adult cancers.
\end{abstract}

Methods-Literature review and epidemiological evaluation.

Results-Seven epidemiological studies have been conducted on the risk of cancer among adults in relation to residential exposure to power frequency magnetic fields. Leukaemia was positively associated with magnetic fields in three casecontrol studies. The other two case-control studies and two cohort studies did not show such a link. Brain tumours and breast cancer have rarely been examined by these studies. Based on the epidemiological results, the analysis of the role of chance and bias, and the criteria for causal inferences, it seems that the evidence is not strong enough to support the putative causal relation between residential exposure to magnetic fields and adult leukaemia, brain tumours, or breast cancer. Inadequate statistical power is far more a concern than selection bias, information bias, and confounding in interpreting the results from these studies, and in explaining inconsistencies between studies.

Department of Epidemiology and Biostatistics

$\mathrm{C}-\mathrm{Y} \mathrm{Li}$

Department of Occupational Health, Faculty of Medicine, McGill University, Montreal, Quebec,

Canada

G Thériault

College of Public

Health, National

Taiwan University,

Taipei, Taiwan,

Republic of China

$\mathrm{R} S \mathrm{Lin}$

Correspondence to: Dr Gilles Thériault,

Department of Occupational

Health, Faculty of Medicine,

McGill University, 1130

Pine Avenue West,

Montreal, Quebec H3A 1A2,

Canada.

Accepted 18 March 1996
Conclusions-Our reviews suggested that the only way to answer whether residential exposure to magnetic fields is capable of increasing the risks of adult cancers is to conduct more studies carefully avoiding methodological flaws, in particular small sample size. We also suggested that the risk of female breast cancer should be the object of additional investigations, and that future studies should attempt to include information on exposure to magnetic fields from workplaces as well as residential exposure to estimate the effects of overall exposure to magnetic fields.

\section{(Occup Environ Med 1996;53:505-510)}

Keywords: magnetic fields; residential exposure; cancer
For over a decade, a controversial question has emerged around the electricity we all depend on: does it have anything to do with cancer? In 1979, Wertheimer and Leeper first suggested a link between exposure to power frequency magnetic fields and certain types of childhood cancer, in particular leukaemia and brain tumours. ${ }^{1}$ Some subsequent studies have added evidence in support of their findings, other studies have found no such link.

Previous studies tended to associate the risk of cancer with either residential or occupational exposure to magnetic fields, and usually evaluated the risk for children and adults separately. Results have been criticised mainly for inadequate exposure assessment. Recently, assessments of magnetic fields in both residential and occupational settings have improved significantly by on site measurements. Several extensive reviews of epidemiological studies on the association between cancer and electric and magnetic fields have been published. ${ }^{2-9}$ Based on these reviews, there seemed to be a tendency suggesting a moderate association with certain types of cancers, such as leukaemia and brain tumours. These findings came mostly from the studies of children and workers. Residential adult studies have not been extensive. This paper reviews residential studies of adult cancers and summarises the epidemiological evidence from these studies for the causal association between exposure to increased residential magnetic fields and risks of adult cancers.

Findings from studies of residential exposure to magnetic fields and adult cancers

To our knowledge, there have been seven epidemiological studies designed to investigate the risk of adult cancers in association with residential exposure to magnetic fields; ${ }^{10-16}$ five casecontrol studies ${ }^{10-14}$ and two cohort studies (table 1). ${ }^{15} 16$ The most important methodological feature of these studies was the strategy used to assess residential magnetic fields. Wertheimer and Leeper, ${ }^{10}$ duplicating the methods of their 1979 study, used wiring configuration in the vicinity of the homes. The same strategy was adopted by Severson et al. ${ }^{11}$ Distance from power transmission lines or substation equip- 
Table 1 Methodology of epidemiological studies of residential exposure to power frequency magnetic fields and adult cancers

\begin{tabular}{|c|c|c|}
\hline Reference, study area, period & Study subjects & Exposure assessment \\
\hline $\begin{array}{l}\text { Wertheimer and Leeper }{ }^{10} \\
\text { Colorado, } 1967-75 \text { and } 1977\end{array}$ & $\begin{array}{l}\text { Case-control studies } \\
\text { Cancer patients dead or alive } \geqslant 19 \text { years, selected from cancer death } \\
\text { certificates or cancer registry; controls were non-cancer deaths or } \\
\text { neighbours of cases } \\
\text { case:control = } 1179: 1179\end{array}$ & Wiring configuration \\
\hline $\begin{array}{l}\text { Severson et al }{ }^{11} \text {, Western } \\
\text { Washington State, 1981-4 }\end{array}$ & $\begin{array}{l}\text { Incidences of acute non-lymphocytic leukaemia aged } 20-79 \text { and } \\
\text { selected from cancer registry; controls were selected from random digit } \\
\text { dialing } \\
\text { case:control = 114:133 }\end{array}$ & $\begin{array}{l}1 \text { Wire configuration } \\
2 \text { One time only magnetic fields measurement } \\
3 \text { Exposure classification based on previous } \\
24 \text { hour magnetic fields measurement }\end{array}$ \\
\hline $\begin{array}{l}\text { Coleman et al }{ }^{12} \text {, South East } \\
\text { England, 1965-80 }\end{array}$ & $\begin{array}{l}\text { Cases were leukaemia of all ages }(n=771) \text { selected from cancer registry; } \\
\text { two control groups were used. "cancer controls" registered with a solid } \\
\text { tumour excluding lymphoma }(n=1432) \text {; "population controls" selected } \\
\text { from electoral roll }(n=231)\end{array}$ & $\begin{array}{l}1 \text { Distance between the residence and } \\
\text { overhead power lines or substation } \\
2 \text { Calculated strength of magnetic fields from } \\
\text { averaged "peak winter load" over three } \\
\text { consecutive winters }\end{array}$ \\
\hline $\begin{array}{l}\text { Youngson et al }{ }^{13} \text {, North West } \\
\text { and Yorkshire regions of } \\
\text { England, 1983-5 }\end{array}$ & $\begin{array}{l}\text { All cases aged } \geqslant 15 \text { and registered with non-Hodgkin's lymphoma or } \\
\text { myeloid leukaemia; controls selected from hospital discharges with } \\
\text { non-malignant disease } \\
\text { case:control = 2113:2113 (lymphoid malignancy); 801:801 (myeloid } \\
\text { leukaemia) }\end{array}$ & $\begin{array}{l}1 \text { Distance from overhead power lines } \\
2 \text { Calculated magnetic fields from maximum } \\
\text { current load in the five years preceding the } \\
\text { key date }\end{array}$ \\
\hline $\begin{array}{l}\text { Feychting and Ahlbom }{ }^{14} \text {, } \\
\text { Sweden, 1960-85 }\end{array}$ & $\begin{array}{l}\text { Cases and controls were selected from a cohort of some } 400000 \text { people } \\
\text { living within } 300 \mathrm{~m} \text { of } 220 / 400 \mathrm{kV} \text { power lines; all subjects aged }>15 \text {. } \\
325 \text { leukaemia; } 223 \text { central nervous system } \\
\text { tumours; } 1091 \text { controls }\end{array}$ & $\begin{array}{l}1 \text { Spot measurement of magnetic fields } \\
2 \text { Calculated strength of magnetic fields from } \\
\text { overhead power lines } \\
3 \text { Distance from over-head power lines }\end{array}$ \\
\hline $\begin{array}{l}\text { McDowall } 15 \text {, East Anglia, } \\
\text { England, 1971-83 }\end{array}$ & $\begin{array}{l}\text { Cohort studies } \\
\text { Retrospective cohort of } 7631 \text { residents of all ages and living within } \\
50 \mathrm{~m} \text { radius of a substation or within } 30 \mathrm{~m} \text { either side of an overhead } \\
\text { power line in the } 1971 \text { census. Expected deaths were calculated from } \\
\text { regional general population } \\
\text { Person years at risk }=91016\end{array}$ & $\begin{array}{l}\text { In the vicinity of electricity transmission } \\
\text { system }\end{array}$ \\
\hline $\begin{array}{l}\text { Schreiber et al }{ }^{16}, \text { Limmel, } \\
\text { The Netherlands, 1961-81 }\end{array}$ & $\begin{array}{l}\text { Retrospective-cohort of } 3549 \text { residents of all ages who have lived in } \\
\text { Limmel, The Netherlands for five years or more between 1961-81; } \\
\text { expected deaths were calculated from Dutch general population. } \\
\text { Person years at risk }=74055\end{array}$ & $\begin{array}{l}\text { In the vicinity of two overhead power lines } \\
\text { and one transformer substation }\end{array}$ \\
\hline
\end{tabular}

ment ${ }^{12-16}$ as well as calculation of fields intensity from load on power lines ${ }^{12-14}$ were frequently used to estimate residential magnetic fields. On site measurements of magnetic fields at residences occupied by study subjects were performed in only two studies. ${ }^{1114}$ On site measurements were also carried out for a few residences in one cohort study to confirm that the average exposure in the houses within 100 metres from the power lines (the primary exposure assessment method) was substantially higher than that in the other houses. ${ }^{16}$

Table 2 shows the main findings of the seven studies. Wertheimer and Leeper suggested a significant association between higher current configuration and all cancers combined. Based on four exposure levels, the odds ratio (OR) of all cancer mortality for exposure to very high current configuration relative to very low current configuration was $2 \cdot 18$ (95\% confidence interval (95\% CI) $1 \cdot 48-3 \cdot 22)$. The OR (95\% CI) was $1.28(1.08-1.52)$ when only two exposure levels (high current configuration $v$ low current configuration) were used. In a casecontrol study of cancer incidence, Severson et $a l^{11}$ found that neither spot measured magnetic fields nor wiring codes were associated with acute non-lymphoid leukaemia (ANLL). Coleman et al ${ }^{12}$ reported a 1.45 -fold increased risk (95\% CI $0.54-3.88)$ of leukaemia among people living within 100 metres of power lines. Results from the study of Coleman et al were supported in part by Youngson et al ${ }^{13}$ who suggested a moderate association between myeloid leukaemia (ML) and residential proximity to overhead lines, and a stronger association with estimated intensity of magnetic fields. Living within 100 metres of overhead transmission lines was associated with a relative risk estimate of $1.39(95 \%$ CI $0.82-2.53)$ for ML. The relative risk estimate, with $<0 \cdot 1$ milligauss $(\mathrm{mG})$ as a reference level, for magnetic fields $\geqslant 1.0 \mathrm{mG}$ was 3.00 (95\% CI 0.81-11.08). No association between magnetic fields and lymphoid malignancies was found. A recent Swedish study by Feychting and Ahlbom ${ }^{14}$ showed an increased relative risk estimate of both acute myeloid leukaemia (AML) (OR 1.7, 95\% CI 0.8-3.5) and chronic myeloid leukaemia (CML) (OR $1 \cdot 7,95 \%$ CI $0 \cdot 7-3 \cdot 8$ ) for people living with estimated magnetic fields $\geqslant 2 \mathrm{mG}$, compared with people exposed to $<1 \mathrm{mG}$. The relative risk estimates for chronic lymphatic leukaemia (CLL) and tumours of the central nervous system (CNS) were close to one. The cumulative exposure within 15 years before diagnosis was also found to be associated with the risks of AML (OR 1.9, 95\% CI 0.6-4.7) and CML (OR 2.7, 95\% CI 1.0-6.4). The two cohort mortality studies ${ }^{1516}$ provided no evidence for the hypothesis that magnetic fields increase risks of certain types of cancer.

For leukaemia in general, three case-control studies ${ }^{12 \cdot 14}$ found an increased risk for residence with increased exposure to magnetic fields. The excess risks found in these studies, however, were not significant. The other two case-control studies ${ }^{1011}$ and the two cohort studies ${ }^{1516}$ did not find such an association. For cell specific leukaemia, Youngson et al linked magnetic fields to $\mathrm{ML}$, which was consistent with the findings by Feychting and Ahlbom reporting an equally increased relative risk estimate for $\mathrm{AML}$ and CML, but not for CLL.

An estimate summarising the magnitude of the risks of leukaemia can be obtained by pooling four case-control studies ${ }^{11-14}$ or two cohort studies $^{1516}$ together. The Mantel-Haenszel method, ${ }^{17}$ with weighted average of study specific risk estimates, was used to measure the pooled relative risk estimate for case-control studies. The summary estimate derived from 
Table 2 Main findings from studies of residential exposure to magnetic fields and adult cancers *

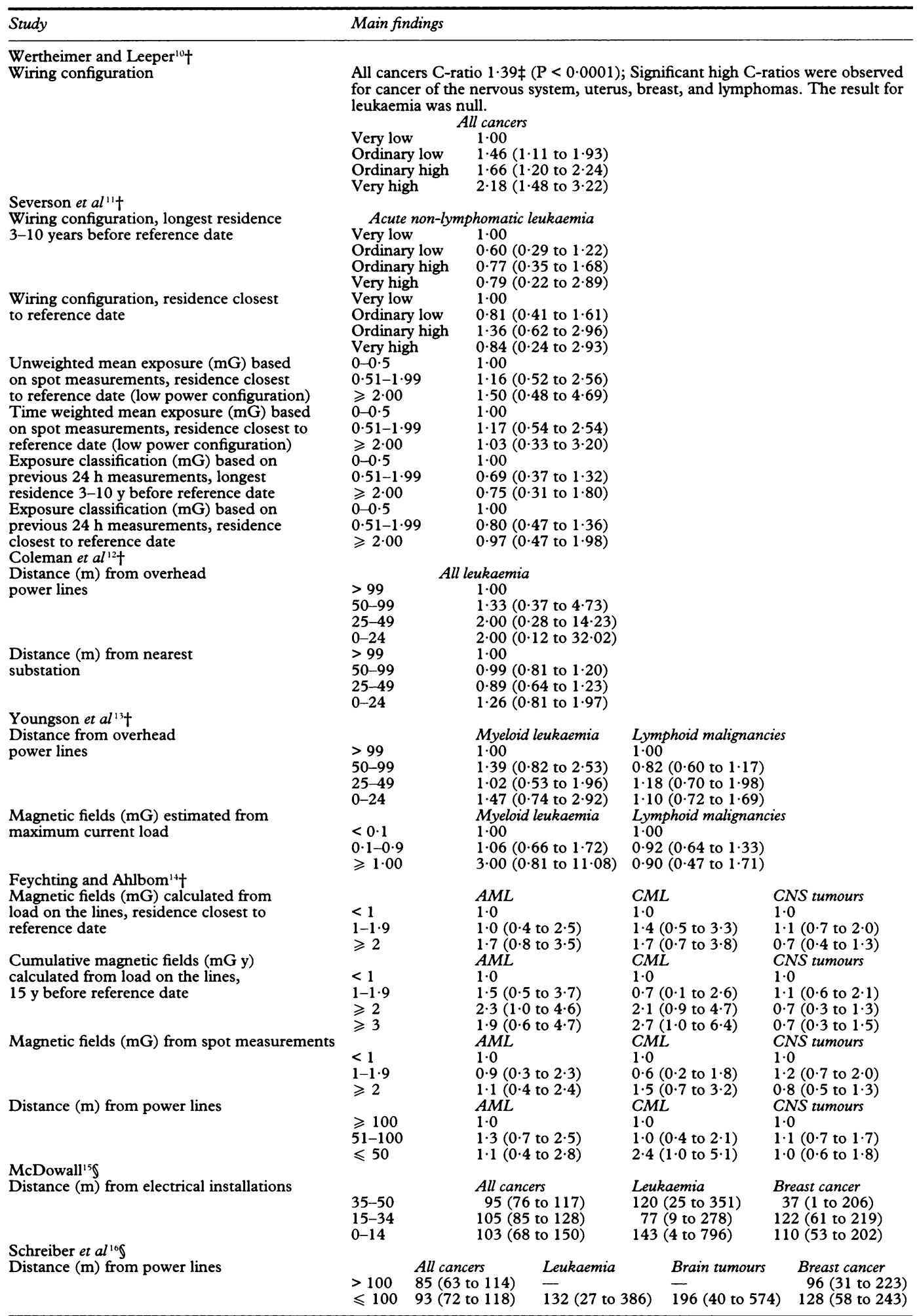

*When relative risk estimates and CI's are not presented in the original papers, they were calculated from available data. Some relative risk estimates were calculated from recategorised exposures for the purpose of comparisons.

†Results in OR (95\% CI).

FC-ratio: ratio of number of matched pairs with "exposed" cases to number of matched pairs with "exposed" controls.

SResults in SMR ( $95 \% \mathrm{CI})$.

$\mathrm{OR}=$ odds ratio; $\mathrm{AML}$ = acute myeloid leukaemia; $\mathrm{CML}=$ chronic myeloid leukaemia; $\mathrm{CNS}=$ central nervous system; $\mathrm{SMR}=$ standardised mortality ratio; $\mathrm{mG}=$ milligauss.

pooling the two cohort studies was calculated as the ratio between the sum of observed cases and the sum of expected cases derived from the published data, weighted proportionally to the size of the population for each study. ${ }^{18} \mathrm{We}$ collapsed exposure into three categories for calculating the summary $O R$ and treated the entire population that were considered to have had more than background exposure in the two cohort studies as being exposed for computing the summary standardised mortality ratio (SMR). The pooled OR (95\% CI) for leukaemia (including all leukaemia and cell specific leukaemia) was $1.01(0 \cdot 77-1 \cdot 30)$ for people with moderate exposure; and $1 \cdot 17$ $(0 \cdot 90-1 \cdot 52)$ for highly exposed people. For the 
Table 3 Statistical power of studies to detect relative risk of adult cancers for people with high exposure to residential magnetic fields

\begin{tabular}{|c|c|c|c|}
\hline Study & Main contrasts & Type of cancer & Power $^{\star}$ \\
\hline Wertheimer and Leeper ${ }^{10}$ & VHCC $v$ VLCC & All cancers & 0.72 \\
\hline \multirow[t]{2}{*}{ Severson et al } & VHCC $v$ VLCC & Acute non-lymphoid leukaemia & 0.45 \\
\hline & $\geqslant 2 \mathrm{mG} v \leqslant 0.5 \mathrm{mG}$ & Acute non-lymphoid leukaemia & 0.57 \\
\hline \multirow{2}{*}{ Coleman et al ${ }^{12}$} & $0-24 \mathrm{~m} v \geqslant 100 \mathrm{~m}$ from power lines & All leukaemia & 0.43 \\
\hline & $0-24 \mathrm{~m} v \geqslant 100 \mathrm{~m}$ from substations & All leukaemia & 0.94 \\
\hline \multirow[t]{3}{*}{ Youngson et al ${ }^{13}$} & $0-24 \mathrm{~m} v \geqslant 100 \mathrm{~m}$ from transmission lines & Myeloid leukaemia & 0.99 \\
\hline & $0-24 \mathrm{~m} v \geqslant 100 \mathrm{~m}$ from transmission lines & $\begin{array}{l}\text { Lymphoid malignancies } \\
\text { Myeloid leukaemia }\end{array}$ & $\begin{array}{l}0.95 \\
0.16\end{array}$ \\
\hline & $\geqslant 1 \mathrm{mG} v<0.1 \mathrm{mG}$ & Lymphoid malignancies & 0.75 \\
\hline \multirow[t]{4}{*}{ Feychting and Ahlbom ${ }^{14}$} & $\geqslant 2 \mathrm{mG} v<0.1 \mathrm{mG}$ from calculation & Acute myeloid leukaemia & 0.48 \\
\hline & $\begin{array}{l}\geqslant 2 \mathrm{mG} v<0.1 \mathrm{mG} \text { from calculation } \\
\geqslant 2 \mathrm{mG} v<0.1 \mathrm{mG} \text { from calculation }\end{array}$ & $\begin{array}{l}\text { Chronic myeloid leukaemia } \\
\text { Central nervous system tumours }\end{array}$ & $\begin{array}{l}0.41 \\
0.94\end{array}$ \\
\hline & $\geqslant 2 \mathrm{mG} v<0.1 \mathrm{mG}$ from spot measurements & Acute myeloid leukaemia & 0.46 \\
\hline & $\geqslant 2 \mathrm{mG} v<0.1 \mathrm{mG}$ from spot measurements & Chronic myeloid leukaemia & $\begin{array}{l}0.46 \\
0.88\end{array}$ \\
\hline \multirow[t]{2}{*}{ McDowall ${ }^{15}$} & Exposed population $v$ general population & $\begin{array}{l}\text { Leukaemia } \\
\text { Leutral nervous system tumours }\end{array}$ & $0 \cdot 17$ \\
\hline & Exposed population $v$ general population & Breast cancer & 0.97 \\
\hline \multirow[t]{3}{*}{ Schreiber $e t a l^{16}$} & Exposed population $v$ general population & Leukaemia & $0 \cdot 17$ \\
\hline & Exposed population $v$ general population & Brain tumours & $0 \cdot 17$ \\
\hline & Exposed population $v$ general population & Breast cancer & 0.59 \\
\hline
\end{tabular}

*Power to reject a null effect at the 0.05 significance level if in fact the true relative risk estimate is two.

VHCC = very high current configuration; VLCC = very low current configuration.

cohort studies combined, the SMR (95\% CI) for the exposed population was 1.15 $(0 \cdot 57-2 \cdot 65)$. An examination of pooled relative risk estimates from both case-control and cohort studies suggested that there is only a slightly increased risk (about 15\%) of leukaemia for people with exposure to increased residential magnetic fields. However, this weak association was not significant. Also, caution must be exercised in interpreting the results from this analysis as the methodology was not uniform across the studies. ${ }^{19}$

The results from two case-control studies ${ }^{1014}$ and one cohort study ${ }^{16}$ which investigated the risk of CNS tumours were also inconsistent. The study by Wertheimer and Leeper was the only one to report a significantly increased risk of CNS tumours. ${ }^{10}$ The relative risk estimates of the other two studies were either close to one ${ }^{14}$ or very unreliably increased. ${ }^{16}$ No cell specific risks of CNS tumours were analysed in these studies.

The risk of breast cancer was studied in one case-control study ${ }^{10}$ and two cohort studies. ${ }^{15} 16$ Wertheimer and Leeper reported an association between mortality from female breast cancer and wiring configuration. ${ }^{10}$ Their findings were not supported by the two subsequent cohort studies in which the relative risk estimates were close to one.

\section{Discussion}

THE ROLE OF CHANCE

For each study, we calculated its statistical power necessary to reject the null hypothesis of no association at the 0.05 significance level if in fact the true relative risk estimate was two (table 3), with the method of Schlesselman ${ }^{20}$ for case-control studies and that of Breslow and Day $^{21}$ for cohort studies. For case-control studies, prevalence of the exposed population was estimated from the proportion of exposed controls. The results showed that only two studies (Coleman et $a l^{12}$ and Youngson et $a l^{13}$ ) had adequate power $(0 \cdot 8)$ to detect a twofold risk of leukaemia in some of the main contrasts. The study by Feychting and Ahlbom ${ }^{14}$ had an adequate power $(0.88-0.94)$ for the analysis of CNS tumours, but the power was below 0.5 for detecting an excess risk of AML or CML. The two case-control studies which did not support a link between residential magnetic fields and leukaemia ${ }^{1011}$ also had inadequate power for the contrast upon which the conclusions were based. The power to evaluate the risk of leukaemia or brain tumours was low for the two cohort studies ${ }^{1516}$ due to a very small number of deaths in the exposed population. The power for breast cancer analysis was 0.97 and 0.59 for the cohort studies of McDowall ${ }^{15}$ and Schreiber et $a l,{ }^{16}$ respectively.

THE ROLE OF BIAS

There were several potential sources of bias that could have affected the relative risk estimates in these studies. We shall consider three of them: the bias from selection of study subjects in the case-control studies or from incomplete follow up in the cohort studies; the bias from exposure assessment of residential magnetic fields; and the bias from confounding.

Five case-control studies recruited cases from regional cancer registries ${ }^{10-14}$ and assembled controls from several sources: non-cancer deaths and neighbours of cases, ${ }^{10}$ random digit dialing, ${ }^{11}$ cancer registry data excluding lymphoma and electoral roll, ${ }^{12}$ hospital patients with non-malignant diseases, ${ }^{13}$ and community healthy controls. ${ }^{14}$ Given the quality of cancer registries in the study areas, the likelihood that a socioeconomic gradient played a part in the reporting of cancers to the cancer registry was considered very small, which leaves little room for selection bias for cases with increased exposure (presumably exposure is associated with socioeconomic variables) to be recruited. These control selection methods generally are appropriate except that the choice of controls in the study of Coleman et al ${ }^{12}$ created a potential for spuriously low relative risk estimates because CNS tumours were not excluded from the control candidates. The almost complete follow up of the two cohort studies ${ }^{15} 16$ avoided the potential for selection bias due to loss of follow up.

Assessment of residential magnetic fields was essential for the validity and the inferences of these studies. Distance from major power facilities, wiring configurations, and intensity of magnetic fields estimated from load on the 
power lines were three frequently used surrogates for direct measurements of residential magnetic fields and were treated as semiquantitative methods. Short term on site measurements of magnetic fields for each person's residence was carried out in only two studies. ${ }^{11} 14$ Although the mechanism by which magnetic fields interact with the human body has yet to be understood, it is reasonable to assume that prolonged exposure to magnetic fields is required for onset of cancer. Given the fluctuation of magnetic fields within a day, a month, and a year, the semiquantitative methods already described seem more reliable than short term on site measurements to measure long term exposure to magnetic fields. Because there are no convincing data to substantiate this assertion, the possibility that these semiquantitative methods may have produced a misclassification of true exposure at least to some extent should not be completely excluded. Because such exposure misclassification was likely to be non-differential, it might have diluted the real associations in some studies, but would not be a valid argument against studies which reported a carcinogenic effect of magnetic fields. ${ }^{10}$ 12-14

Potential confounders, such as age, sex, year of diagnosis, and socioeconomic status were controlled for in all seven studies. Except for that of Severson et al, ${ }^{11}$ none of these studies controlled for the known leukaemogens such as benzene, ionising radiation, and chemotherapeutic chemicals. Risk factors for brain tumours and female breast cancer were likewise not considered in the studies of CNS tumours, ${ }^{1014-16}$ and female breast cancer. ${ }^{1015} 16$ Nevertheless, an incomplete adjustment for potential confounders might not necessarily represent a significant source of bias, as a factor must be associated with both disease and exposure to produce confounding. There is no clear indication that people living in an environment with increased magnetic fields would have a greater chance of being exposed to the known carcinogens for such cancers. Moreover, two studies have indicated no evidence of disparity in demographic characteristics and socioeconomic indices between people with and without increased residential magnetic fields. ${ }^{22} 23$ Therefore, confounding by known variables is unlikely to explain the results from these studies. However, the likelihood that the associations found in some studies were attributable to confounding by unknown factors could not be completely dismissed, which is particularly essential when relative risk estimates are in the range of $1 \cdot 5$ to $2 \cdot 0$.

\section{APPLYING CRITERIA FOR CAUSAL INFERENCE \\ Consistency of association}

There are no consistent findings for leukaemia. Three ${ }^{12-14}$ out of the seven studies have reported an increased risk. Of them, two reported an increased risk of ML. ${ }^{13} 14$ The increased risk of overall leukaemia was found in the study of Coleman et $\mathrm{Al}^{12}$ but not that of Feychting and Ahlbom. ${ }^{14}$ Among the four studies of CNS tumours, ${ }^{1014-16}$ one reported a positive association. ${ }^{10}$ This was also the only study suggesting an increased risk of female breast cancer among three studies of its kind. ${ }^{1015-16}$ It is noted that the studies with positive results were all based on case-control design. The two cohort studies $^{15}{ }^{16}$ showed no evidence to support any positive associations. Although the overall evidence tends to show an inconsistent risk estimate for leukaemia and no risk for CNS tumours and breast cancer, it must be noted that this tendency was based on few publications.

\section{STRENGTH OF ASSOCIATION AND DOSE-} RESPONSE RELATION

Data of the studies with positive results showed that the relative risk estimates of leukaemia for residential exposure of adults were between 1.5 and 3 . The corresponding risks for CNS tumours were about $2 \cdot 0$. Although there are no well accepted criteria for the strength of an association to confirm a causal relation, a relative risk estimate in the range of 1.5 to 3 with wide CIs is rather low and confounding by some unrecognised variables could potentially account for the associations found. However, this does not rule out a causal relation with a very small relative risk estimate. The only study that showed a dose-response relation was Wertheimer and Leeper's for all cancers in relation to wiring configurations.

\section{BIOLOGICAL COHERENCE AND PLAUSIBILITY}

There are a few hypotheses suggesting the plausibility of a causal relation between magnetic fields and cancer. Among them, two biological effects have been identified and replicated in the laboratory-that is, extremely low frequency electromagnetic fields impact on the production of the hormone melatonin by the pineal gland in whole animals, and on the calcium homeostasis in the cellular system. A substantial amount of experimental data indicated that the effect of extremely low frequency magnetic fields on cellular biochemistry, function, and structure can be related to induced current. However, most of the reported effects occurred at current density levels very much higher than those normally found in occupational or residential settings. ${ }^{24}$ From this perspective, it is still difficult to identify an underlying mechanism that could support any association between magnetic fields and adult cancers.

\section{Conclusions}

Based on the existing epidemiological results, the putative causal relation between residential exposure to magnetic fields and cancers among adults cannot be substantiated at this time mainly because of methodological limitations in the studies. Our review shows that inadequate statistical power is of far more a concern than bias in explaining the inconsistencies across studies. Only two studies ${ }^{1213}$ had adequate power $(0.8)$ to detect a twofold increase in risk of leukaemia, and most studies that do not show a support for increased cancer risks had an inadequate number of subjects with increased exposure. Bias, on the other hand, is not likely to have been responsible for the positive findings, as no obvious indication of selection bias, information bias, and confounding could be identi- 
fied. On the other hand, measurements of magnetic fields were apparently inadequate in most studies, which may have been a source of exposure misclassification.

Some residential adult studies do suggest associations between surrogates of household magnetic fields such as wiring configuration and estimated intensity of magnetic fields and leukaemia with relative risk estimates ranging from 1.5 to 3.0 . The magnitude of these relative risk estimates was compatible with those reported from the studies of children ${ }^{125-27}$ and workers. ${ }^{28}$ However, the results from these studies overall are inconsistent. Our review shows no evidence for dose-response relations; nor is the evidence able to identify the cell specific cancers, if any, most sensitive to magnetic fields. This is mainly due to a shortage of study subjects, which led to a very unstable relative risk estimate for each exposure category or cellspecific cancer group. These uncertainties will remain with little hope for resolution unless additional epidemiological studies with many subjects can be carried out in the future.

It has been recognised that magnetic fields from residential or occupational sources have dissimilar characteristics. Residential exposure is subject to daily and seasonal variations and rarely exceeds several $\mathrm{mG}$; exposure at the workplace generally does not show the same variations and is frequently intermittent with peak intensity on the order of 1 to $100 \mathrm{mG}$, which makes it inappropriate to compare the findings from residential adult studies with the results from occupational studies. It would be of interest for future studies to examine what specific characteristics of magnetic fields are most biologically relevant if any association is real.

The controversial question: do magnetic fields have anything to do with cancer? represents an intriguing scientific problem. Our review shows significant shortcomings in residential adult studies so far and suggests that additional studies should be carried out carefully to avoid methodological flaws, especially inadequate sample size, to help resolve current uncertainties associated with external power lines, the source that contributes most to long term residential exposure to magnetic fields. Considering the overall evidence on the role of residential magnetic fields in the cause of adult cancers, our review also suggests that the following aspects should be considered in future studies. Firstly, the risk of female breast cancer should be the object of additional investigations, not only because this cancer is highly prevalent and has a significant public health implication, but also because women with electrical occupations are few, and the main source of exposure for women is their homes. Secondly, future studies should be devoted to the examination of cell specific risks of leukaemia and brain tumours, as well as the potential dose-response relation between residential magnetic fields and adult cancers. Thirdly, future studies should attempt to include information on exposure to magnetic fields from residences as well as workplaces to estimate the effects of overall exposure to magnetic fields.

1 Wertheimer N, Leeper E. Electrical wiring configurations and childhood cancer. Am $\mathcal{F}$ Epidemiol 1979;109:273-84.

2 Savitz DA, Calle EE. Leukemia and occupational exposures to electromagnetic fields: review of epidemiological surveys. $\mathcal{F}$ Occup Med 1987;29:47-51.

3 Coleman MP, Beral V. A review of epidemiological studies of the health effects of living near or working with electricity generation and transmission equipment. Int $\mathcal{F}$ Epidemiol 1988;17:1-13.

4 Ahlbom A. A review of the epidemiological literature on magnetic fields and cancer. Scand $\mathcal{F}$ Work Environ Health 1988;14:337-43.

5 Savitz DA, Pearce NE, Poole C. Methodological issues in the epidemiology of electromagnetic fields and cancer. Epidemiol Rev 1989;11:59-78.

6 Thériault GP. Health effects of electromagnetic radiation on workers: epidemiological studies. In: Bierbaum PE, Peters JM, eds. Proceedings of the scientific workshop on the Peters JM, eds. Proceedings of the scientific workshop on the health effects of electric and magnetic fields on workers. and Health, 1991:91-111.

7 Thériault G. Electromagnetic fields and cancer risks. Rev Epidém et Santé Publ 1992;40:55-62.

8 Savitz DA, Pearce N, Pool C. Update on methodological issues in the epidemiology of electromagnetic fields and cancer. Epidemiol Rev 1993;15:558-66.

9 Savitz DA, Ahlbom A. Epidemiological evidence on cancer in relation to residential and occupational exposures. In Carpenter DO, Ayrapetyan S, eds. Biological effects of electric and magnetic fields, Vol II. San Diego: Academic tric and magnetic firld

10 Wertheimer N, Leeper E. Adult cancer related to electrical wires near the home. Int $\mathcal{f}$ Epidemiol 1982;11:345-55.

11 Severson RK, Stevens RG, Kaune WT, Thomas DB, Heuser L, Davis S, Sever LE. Acute non-lymphocytic leukemia and residential exposure to power frequency magnetic fields. Am $\mathcal{F}$ Epidemiol 1988;128:10-20.

12 Coleman MP, Bell CMJ, Taylor HL, Primic-Zakelj M. Leukemia and residence near electricity transmission equipment: a case-control study. $B r \mathcal{F}$ Cancer 1989;60: 793-8.

13 Youngson JHAM, Clayden $\mathrm{AD}$, Myers A. A case-control study of adult haematological malignancies in relation to overhead power lines. Br $¥$ Cancer 1991;63:977-85.

14 Feychting M, Ahlbom A. Magnetic fields, leukemia, and central nervous system tumors in Swedish adults residing near high-voltage power lines. Epidemiology 1994;5: $501-9$.

15 McDowall ME. Mortality of persons resident in the vicinity of electricity transmission facilities. Br $\mathcal{F}$ Cancer 1986;53: 271-9.

16 Schreiber GH, Swaen GMH, Meijers JMM, Slangen JM, Sturmans F. Cancer mortality and residence near electricity transmission equipment: a retrospective cohort study In F Epidemiol 1993;22:9-15.

17 Mantel N, Haenszel W. Statistical aspects of the analysis of data from retrospective studies of disease. $₹$ Natl Cancer Inst 1959;22:719-48.

18 Rothman KJ, Boice JD. Epidemiologic analysis with a programmable calculator. Chestnut Hill: Epidemiology Resources, 1982:29-30

19 Greenland S. Quantitative methods in the review of epidemiologic literature. Epidemiol Rev 1987;9:1-30.

20 Schlesselman J. Case-control studies, design, conduct, analysis. New York: Oxford University Press, 1982:144-70.

21 Breslow NE, Day NE. Statistical methods in cancer research, volume II-the design and analysis of cohor studies. Lyon: IARC, 1987:273-9.

22 Salzberg MR, Farish SJ, Delpizzo V. An analysis of association between social class and ambient magnetic fields in tion between social class and ambient magnetic fields in metrop

23 Wartenberg $D$, Greenberg $M$, Lathrop $R$. Identification and characterization of populations living near high-voltage transmission lines: a pilot study. Environ Health Perspect 1993;101:626-32.

24 Wilson BW, Stevens RG, Anderson LE. Extremely low frequency electromagnetic fields: the question of cancer. Columbus, OH: Battelle Press, 1990:295-318.

25 Savitz DA, Wachtel H, Barnes FA, John EM, Tvrdik JG. Case-control study of childhood cancer and exposure to 60-Hz magnetic fields. Am 7 Epidemiol 1988;128:21-8.

26 London SJ, Thomas DC, Bowman JD, Sobel E, Cheng TC, Peters JM. Exposure to residential electric and magnetic fields and risk of childhood leukemia. $\mathrm{Am} \mathfrak{f}$ netic fields and risk of chil
Epidemiol 1991;134:923-37.

27 Feychting M, Ahlbom A. Magnetic fields and cancer in children residing near Swedish high-voltage power lines. children residing near Swedish high

28 ORAU Panel on Health Effects of Low-Frequency Electric and Magnetic Fields. Health effects of low-frequency electric and magnetic fields. Oak Ridge, TN: Oak Ridge Associated Universities, 1992:V1-58 